\title{
HOMENAJE A \\ ALFONSO REYES \\ (1889-1959)
}

OFRECIDO POR LA SECCION SPANISH 7 :

SPANISH.AMERICAN LITERATURE OF THE TWENTIETH

CENTURY DE IA MODERN LANGUAGE ASSOCIATION DE USA.

EL DIA 29 DE DICIEMBRE DE I964. EN EL HOTEL COLONIAL ATLANTIC DE NEW YORK. 
